\section{Tropical climatology}

Tropical Climatology: An Introduction to the Climates of the Low Latitudes. By S. Nieuwolt. Pp. 207. (Wiley: London, Sydney, New York and Toronto, 1977.) £6.75; $\$ 15$.

Tropical Climatology is primarily intended for students studying geography at Universities within the tropics, though it contains much information useful to students working elsewhere. The level is about that of a first-year geography course in a British University. The book assumes that the reader has some basic knowledge of general climatology, but only a limited knowledge of mathematics and physics. According to the author, the book takes a geographical viewpoint, which concentrates on the results of the physical processes in the atmosphere, and their importance to mankind, rather than on the processes themselves. The book covers most aspects of tropical climatology, including the general circulation of the tropical atmosphere, tropical disturbances, precipitation and applied tropical climatology.

Nieuwolt starts his book with a discussion on the term "tropics" and the distinguishing features of "tropical climates". In the early chapters on radiation and temperature, he continues to stress the general uniformity within the deep tropics. These chapters would have been improved by the introduction of a discussion of the energy balance of vegetated and dry surfaces, as the tropics are not uniformally wet. Evaporation limits the temperature over wet surfaces to $32{ }^{\circ} \mathrm{C}$ or below, whereas over dry surfaces it can rise to much higher values.

Nieuwolt devotes the last half of his book largely to aspects of water in the tropical atmosphere. He starts with a brief discussion of evapotranspiration, humidity, condensation and clouds. The principles of evapotranspiration are explained in clear simple terms. The nature of tropical clouds are discussed, together with their relationship to precipitation patterns. Tropical rainfall is discussed, together with theorics of its formation.

Nieuwolt ends his book with a chapter on applied tropical climatology. Here he suggests that one field in which tropical climates can make significant contributions to the world's economy is in the generation of power. Thus, the high amounts of rainfall which are regularly received in many elevated areas of the tropics, constitute a reliable basis for the construction of hydroelectric power stations. The author claims that about $55 \%$ of the world's total potential of this form of energy is located in the tropics. Solar energy is another source of power in which the tropics are potentially rich, particularly where the seasonal variations in actual hours of sunshine are relatively small. Nevertheless, Nieuwolt states that the main function of the tropical climates as a natural resource is in relation to agriculture, and he considers both solar radiation and rainfall in relation to tropical crop production.

The book as a whole is easy to read, well produced, and forms an excellent introduction to the climatology of the tropics. It should be ideal for University geography students studying within the tropics and in particular those living in
Africa. Temperate latitude students will find that their needs are better served by such books as Introduction to the Atmosphere by H. Riehl (McGraw-Hill, 1965) and Atmosphere, Weather and Climate by R. G. Barry and R. J. Chorley (Methuen, third edition, 1976). Even so, they will find it a useful book for additional reading on introductory courses.

\section{J. G. Lockwood}

J. G. Lockwood is Senior Lecturer in the School of Geography at the University of Leeds, UK.

\section{Oceanographic sciences}

MODERN BOOKS, like modern museums, seem able to display their exemplary contents in attractive, eye-catching ways. Four recently published books on the oceanographic sciences are well made and well illustrated; their style is comparable but they vary in their aims and in the extent to which they suceed in achieving them.

To me the most visually attractive is that of J. G. Harvey: Atmosphere and Ocean: Our Fluid Environments (Artemis: Horsham, Sussex, UK, £3.75). Although the cheapest of the four it has good paper, clear print and is well illustrated. It also seems to me the least presumptuous-writing for those with no previous knowledge of meteorology and oceanography and with little physics or mathematics, the author states results rather than proving them, with enough supporting argument to make them seem reasonable. To give an example of his scope: group velocity is mentioned; mesoscale oceanic eddies and double diffusive convection not. I share the author's view that there are benefits to be gained from studying the atmosphere and the ocean together: his book is a useful introduction for non-specialists.

The Ocean-Atmosphere System (Longman: London, £5.50) by A. H. Perry and J. M. Walker, sounds, and is, more portentous. The authors have taken on a harder task, seeking to "treat meteorology, climatology and physical oceanography" for more advanced students in "the broad fields of geography, geophysics, environmental science, marine biology and nautical studies". It seems to me doubtful that such an aim can be achieved: specialised branches of fluid mechanics surely need a good grounding in the the fundamentals? To me their treatment is too historico-geographical, too prone to quote detail rather than basic principle, too broad and too shallow. Again as an example: group velocity is not mentioned, though there are ritual references to Lamb's treatise and Phillips' monograph. As well as the extensive references, there are explanatory notes to each chapter: "Isotropic turbulence is determined solely by the nature of the surface over which the wind blows ..." is an (I hope atypical) example. The classic temperature-salinity diagram is briefly (and incompletely) described in the appendix. The book is an attempt to fill a gap in the literature but the gaps seems likely to continue to exist, as it is between differently trained people.

F. P. Shepard, the author of Geological Oceanography: Evolution of Coasts, Continental Margins and the Deep-Sea Floor (Crane, Russach: New York, \$10.50), is an emeritus professor at the Scripps Institution of Oceanography who was a pioneer in the subject and has been contributing to it for over 50 years. His book is intended for beginning students and for the general public-it is descriptive, with lots of charts, diagrams and photographs but no formulae. The chapter on waves and currents is less authoritative than the others: no group velocity, and a bit shaky on wave velocity; but it has useful advice for surfers and for swimmers in rip currents or on a coral reef. The marine geology is confident and clear, if perhaps a bit discursive. Redolent of the Pacific, rather than the Atlantic or Mediterranean, I was sorry not to see some reference to side-scan sonar or to modern magnetic methods. Professor Shepard has written an interesting introduction rather than a textbook.

Oceanography: A View of the Earth (Prentice-Hall: Englewood Cliffs, New Jersey, $£ 13.55$ ) by M. Grant Cross, is on a bigger scale than the others: more than twice the pages, more than twice the cost. It is the second edition (first in 1972) of his attempt to survey oceanography (marine physics, marine geology and geophysics, marine biology, a little marine chemistry) for beginning students or for those who need only a nodding acquaintance with the science of the sea. In this examples, he gives a good description of group velocity (though not using it in a later section) but regards sonar as a method for the sonic detection of other vessels or objects and for underwater he has to a great extent succeeded: as 